\title{
C-reactive protein in the very early phase of acute ischemic stroke: association with poor outcome and death
}

\author{
H. M. den Hertog $\cdot$ J. A. van Rossum $\cdot$ H. B. van der Worp • \\ H. M. A. van Gemert $\cdot$ R. de Jonge $\cdot$ P. J. Koudstaal · \\ D. W. J. Dippel $\cdot$ the PAIS investigators
}

Received: 19 January 2009/Revised: 17 June 2009/ Accepted: 30 June 2009/Published online: 17 July 2009

(C) The Author(s) 2009. This article is published with open access at Springerlink.com

\begin{abstract}
Acute ischemic stroke may trigger an inflammatory response that leads to increased levels of C-reactive protein (CRP). High levels of CRP may be associated with poor outcome because they reflect either an inflammatory reaction or tissue damage. We evaluated the prognostic value of CRP within $12 \mathrm{~h}$ of onset of ischemic stroke. Levels of CRP were routinely obtained within $12 \mathrm{~h}$ of symptom onset in 561 patients with ischemic stroke. CRP values were dichotomized as $<7$ or $\geq 7 \mathrm{mg} / \mathrm{L}$. The full range of CRP values was used to detect a possible level-risk relationship. We studied the relation between CRP values and poor outcome (modified Rankin Scale score $>2$ ) or death at 3 months. A multiple logistic regression model was applied to adjust for age, sex, NIHSS score, current cigarette smoking, diabetes mellitus, hypertension, statin use, and stroke subtype. After adjustment for potential confounders, patients with CRP levels $\geq 7 \mathrm{mg} / \mathrm{L}$ had a significantly increased risk of poor outcome (adjusted OR 1.6, 95\% CI 1.1-2.4) or death
\end{abstract}

H. M. den Hertog $(\bowtie)$ · J. A. van Rossum · R. de Jonge .

P. J. Koudstaal - D. W. J. Dippel

Department of Neurology,

Erasmus MC University Medical Center Rotterdam, PO Box 2040, 3000 CA Rotterdam, The Netherlands e-mail: m.denhertog@erasmusmc.nl

H. B. van der Worp

Rudolf Magnus Institute of Neuroscience,

University Medical Center Utrecht,

Utrecht, The Netherlands

H. M. A. van Gemert

Meander Medical Center, Amersfoort, The Netherlands (adjusted OR 1.7, 95\% CI 1.0-2.9) at 3 months. In addition, the risk of poor outcome or death at 3 months increased with higher levels of CRP. CRP within $12 \mathrm{~h}$ of ischemic stroke is an independent prognostic factor of poor outcome at 3 months.

Keywords C-reactive protein - Ischemic stroke . Clinical outcome $\cdot$ Prognostic factor $\cdot$ Inflammation

\section{Background}

Elevated serum levels of C-reactive protein (CRP) are found in up to three quarters of patients with ischemic stroke $[8,26]$. Increases in CRP may reflect a systemic inflammatory response following ischemic stroke, the extent of tissue injury, or concurrent infections. Moreover, in animal models of focal cerebral ischemia, CRP increased secondary brain damage through activation of the complement system [13, 22].

Several studies have assessed the value of CRP in the very early phase of stroke as a prognostic factor of functional outcome. These studies were either small, included a selected group of patients, or tested only the relation between CRP and mortality instead of functional outcome. The findings were inconclusive as some found a positive association $[6,18,20]$, but others not $[27,30]$.

Verification of the role of CRP as an early prognostic factor of functional outcome after ischemic stroke may be of clinical importance, because it is an easily-measured and readily available inflammatory marker. The aim of our study was therefore to determine the prognostic value of CRP measured in the very early phase of ischemic stroke for poor functional outcome and death in a large sample of patients with acute ischemic stroke. 


\section{Methods}

\section{Study design}

All patients included in the present study participated in the Paracetamol (Acetaminophen) In Stroke (PAIS) trial, a multicenter, randomized, placebo-controlled clinical trial of high-dose paracetamol in patients with acute stroke. The study protocol has been published earlier [7, 28]. In short, patients with ischemic stroke or intracerebral hemorrhage within $12 \mathrm{~h}$ of symptom onset with no history of liver disease or pre-stroke impairment (modified Rankin Scale (mRS) score $<2$ ) [29] were included in this study. Patients with ischemic stroke included in the PAIS trial between March 2003 and March 2007 in centers where CRP was measured as a part of routine laboratory assessment on admission were included in the present study if venous blood sampling for CRP was accomplished within $12 \mathrm{~h}$ of symptom onset.

\section{Baseline variables}

Baseline clinical information was extracted from the trial records. This included body temperature on admission and $24 \mathrm{~h}$ later, stroke subtype according to the TOAST classification [1], stroke severity as assessed with the NIH Stroke Scale (NIHSS) [5], and cardiovascular risk factors. In addition, the occurrence of infections during hospitalization was assessed. Body temperature was measured with either tympanic or rectal thermometers.

\section{Blood samples and CRP assay}

Blood samples for assessment of CRP and white blood cell count were taken on admission. The time of CRP measurement relative to stroke onset was recorded in all patients.

Levels of CRP were determined with a clinically validated assay. Participating centers used different analyzers (Dade Behring, Beckman LX-20, Beckman Synchron, Beckman Coulter DXC, Olympus 640, Ortho Vitros, Roche Cobas 6000, Roche Cobas Integra, Roche Hitachi 917, Roche Modular) to establish CRP levels. Intra- and interassay variation of all participating centers was evaluated by means of the external quality control scheme of the Dutch Foundation for Quality Assessment in Clinical Laboratories (SKML). If the intra-assay and/or inter-assay coefficient of variation was higher than $7.5 \%$, patients from these centers were excluded from further analysis. All centers were subjected to quality review by the Dutch Foundation for Quality Assessment in Clinical Laboratories (SKML (http://www.skml.nl).

Some centers did not report exact values of CRP below a certain cut-off point, as values below these cut-off points were considered "normal" values. These cut-off points varied between 1 and $7 \mathrm{mg} / \mathrm{L}$.

As extremely high levels of CRP likely reflect an infection at the time of blood sampling, patients in whom the level of CRP was higher than 2 SD above the mean were excluded from further analysis.

\section{Outcome measures}

Poor outcome was defined as a score of more than 2 on the mRS, including death, at 3 months from stroke onset. A secondary outcome was death at 3 months. Outcome was assessed without knowledge of baseline CRP levels.

\section{Statistical analysis}

Statistical analyses were performed with Stata/SE 8.2 for Windows (Statacorp, College Station, Texas, USA). The relation between outcome and dichotomized CRP levels was expressed as an odds ratio (OR), with a corresponding 95\% confidence interval (CI), through logistic regression.

CRP values were dichotomized at $7 \mathrm{mg} / \mathrm{L}$. This cut-off point was selected, as this was the highest cut-off point below which values were considered normal and not reported as exact values by some centers. In order to study a possible level-risk relationship, all CRP values were recoded with $7 \mathrm{mg} / \mathrm{L}$ as the lower bound. Odds ratios were expressed per unit increase in logarithmically transformed CRP levels. Adjustments for the impacts of age, sex, baseline NIHSS score, cigarette smoking status, diabetes mellitus, hypertension, statin use, and stroke subtype (cardioembolic stroke versus non-cardioembolic stroke) was made with multiple logistic regression. We performed additional analyses to account for the potential confounding effect of antipyretic treatment by stratifying for treatment with acetaminophen.

\section{Results}

Between 1 March 2003 and 1 March 2007, 1187 patients were included in the PAIS trial. Sixteen of the 29 participating centers routinely performed CRP measurements on admission for acute stroke. In these 16 centers, 897 patients where included in the PAIS trial in the period under study. Of these patients, 336 were excluded from the present study because of hemorrhagic stroke $(n=117)$, CRP measurement not accomplished within $12 \mathrm{~h}$ of stroke onset or time of assessment unknown $(n=54)$, CRP measurements with analyzers with a variation coefficient $>7.5 \%$ $(n=56)$, or CRP levels over $110 \mathrm{mg} / \mathrm{L}(2 \mathrm{SD} ; n=9)$.

The median CRP level was $5 \mathrm{mg} / \mathrm{L}$ (IQR 2-8) and 33\% of patients had CRP levels of $7 \mathrm{mg} / \mathrm{L}$ or above. 
Table 1 shows the baseline characteristics of the patients with CRP levels $<7$ or $\geq 7 \mathrm{mg} / \mathrm{L}$. Median time from onset of symptoms to CRP measurement was 137 min (range 0696). Patients with CRP $\geq 7 \mathrm{mg} / \mathrm{L}$ were older, had higher scores on the NIHSS, had a slightly higher body temperature on admission, were more often smokers, more frequently had hypertension, diabetes mellitus, or atrial fibrillation, and less often used statins than patients with low CRP levels. Cardioembolic strokes were observed more often in patients with CRP $\geq 7 \mathrm{mg} / \mathrm{L}$.

Sixteen patients with $\mathrm{CRP} \geq 7 \mathrm{mg} / \mathrm{L}$ (9\%) and 15 patients (4\%) with $\mathrm{CRP}<7 \mathrm{mg} / \mathrm{L}$ developed an infection during hospitalization. Two patients with CRP $\geq 7 \mathrm{mg} / \mathrm{L}$ had an infection (both pneumonia) within $24 \mathrm{~h}$ of stroke onset. No infections within $24 \mathrm{~h}$ were reported in patients with $\mathrm{CRP}<7 \mathrm{mg} / \mathrm{L}$.

No association between CRP levels and the body temperature at $24 \mathrm{~h}$ after study enrollment was found.

Patients with CRP levels $\geq 7 \mathrm{mg} / \mathrm{L}$ more often had a poor outcome (57 versus $42 \% ; p=0.006$ ) or died (23 versus $13 \% ; p=0.0007)$ than patients with lower CRP levels (Fig. 1). Adjustment for potential confounders did not change these results (Table 2).

An additional stratified analysis to account for the potential confounding effect of treatment with acetaminophen did not affect the association.

A level-risk relationship was observed between CRP and poor outcome or death at 3 months. The relation
Table 1 Baseline characteristics of the study population a Scores on the National Institutes of Health Stroke Scale (NIHSS) range from 0 to 42 , with higher values indicating more severe stroke [5]

b Based on the definitions of the Trial of ORG 10172 in Acute Stroke Therapy (TOAST) criteria [1]

\begin{tabular}{|c|c|c|c|}
\hline & $\mathrm{CRP}<7 \mathrm{mg} / \mathrm{L}$ & $\mathrm{CRP} \geq 7 \mathrm{mg} / \mathrm{L}$ & $p$ \\
\hline \multicolumn{4}{|l|}{ Demographics } \\
\hline$N$ & 377 & 184 & 0.07 \\
\hline Age (years), mean (SD) & $69.1(13.4)$ & $70.9(13.8)$ & 0.98 \\
\hline Male & $226(60 \%)$ & $110(60 \%)$ & \\
\hline \multicolumn{4}{|l|}{ Stroke severity ${ }^{\mathrm{a}}$} \\
\hline NIHSS, mean (SD) & $7.5(6.0)$ & $8.9(6.6)$ & 0.02 \\
\hline \multicolumn{4}{|l|}{ Risk factors } \\
\hline Arterial hypertension & $183(49 \%)$ & $107(58 \%)$ & 0.03 \\
\hline Atrial fibrillation & $47(12 \%)$ & $47(26 \%)$ & 0.0005 \\
\hline Diabetes mellitus & $50(13 \%)$ & $37(20 \%)$ & 0.03 \\
\hline Current cigarette smoking & $108(29 \%)$ & $70(38 \%)$ & 0.03 \\
\hline Hypercholesterolemia & $104(28 \%)$ & $42(23 \%)$ & 0.30 \\
\hline \multicolumn{4}{|l|}{ History } \\
\hline Stroke & $84(22 \%)$ & $40(22 \%)$ & 0.68 \\
\hline Myocardial infarction & $47(12 \%)$ & $25(14 \%)$ & 0.92 \\
\hline Peripheral vascular disease & $25(7 \%)$ & $21(11 \%)$ & 0.09 \\
\hline \multicolumn{4}{|l|}{ Physical examination } \\
\hline Systolic blood pressure, mean (SD) & $169(31)$ & $171(34)$ & 0.63 \\
\hline Diastolic blood pressure, mean (SD) & $89(18)$ & $89(21)$ & 0.81 \\
\hline Body temperature, mean (SD) & $36.9(0.6)$ & $37.0(0.6)$ & 0.08 \\
\hline \multicolumn{4}{|l|}{ Laboratory assessments } \\
\hline Time until CRP measurement (min), median (range) & $140(2-696)$ & $129(0-681)$ & 0.64 \\
\hline Leukocytes $10^{9} / \mathrm{L}$, mean (SD) & $8.2(2.6)$ & $9.4(3)$ & 0.0001 \\
\hline \multicolumn{4}{|l|}{ Stroke type $(\text { TOAST) })^{b}$} \\
\hline Undetermined & $189(50 \%)$ & $81(44 \%)$ & 0.09 \\
\hline Large vessel disease ( $\geq 50 \%$ stenosis $)$ & $38(10 \%)$ & $28(15 \%)$ & 0.06 \\
\hline Cardiac source of embolism & $60(16 \%)$ & $44(24 \%)$ & 0.02 \\
\hline Small vessel occlusion & $49(13 \%)$ & $24(13 \%)$ & 0.88 \\
\hline Other determined etiology & $41(11 \%)$ & $7(4 \%)$ & 0.003 \\
\hline \multicolumn{4}{|l|}{ Treatment } \\
\hline RtPA & $95(25 \%)$ & $50(27 \%)$ & 0.42 \\
\hline Ace inhibitor & $65(17 \%)$ & $38(21 \%)$ & 0.46 \\
\hline Statin & $101(27 \%)$ & $36(20 \%)$ & 0.001 \\
\hline
\end{tabular}




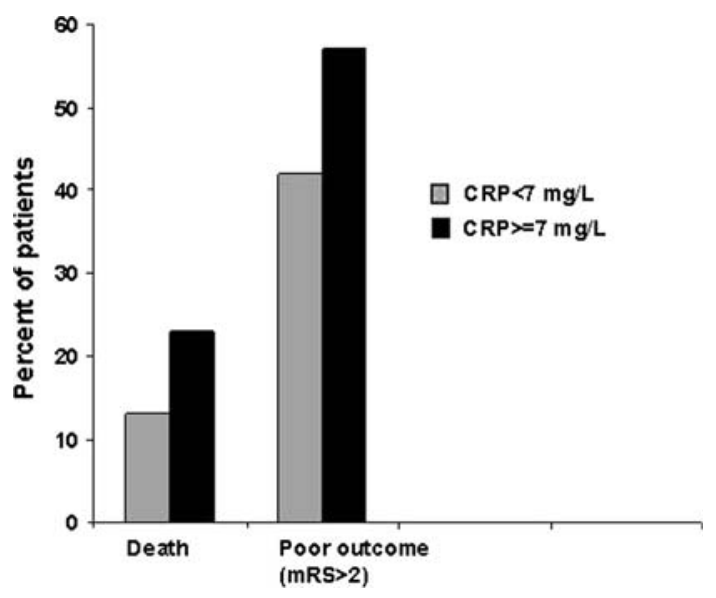

Fig. 1 Association of CRP levels on admission with poor outcome or death at 3 months

Table 2 Association between increased CRP ( $\geq 7 \mathrm{mg} / \mathrm{L})$ at baseline and outcome after ischemic stroke

\begin{tabular}{lll}
\hline & OR $(95 \% \mathrm{CI})$ & Adjusted OR $(95 \% \mathrm{CI})^{\mathrm{a}}$ \\
\hline Poor outcome $(\mathrm{mRS}>2)$ & $1.9(1.3-2.7)$ & $1.6(1.1-2.4)$ \\
Death & $2.0(1.3-3.2)$ & $1.7(1.0-2.9)$ \\
\hline
\end{tabular}

a Adjusted for age, sex, NIHSS score, cigarette smoking, diabetes mellitus, hypertension, statin use, and stroke subtype

between CRP and poor outcome was attenuated after adjustment for potential confounders (Table 3 ).

After exclusion of patients who developed an infection during the first 2 weeks after stroke onset, the adjusted odds ratio for poor outcome was 1.5 (95\% CI 1.0-2.3; $p=0.07)$, and for death 1.9 (95\% CI 1.1-3.4).

\section{Discussion}

In this study, patients with CRP levels $\geq 7 \mathrm{mg} / \mathrm{L}$ within $12 \mathrm{~h}$ of ischemic stroke onset had a significantly increased risk of poor functional outcome or death at 3 months, even after adjustment for potential confounders. In addition, a level-risk relationship was found between CRP and poor outcome and death.

Several studies have found an association between increased CRP levels and clinical outcome in the time window between 12 and $72 \mathrm{~h}$ after ischemic stroke [6, 8, 9, $15,18,20,21,25-27,30]$. The results of previous studies that have aimed to assess the prognostic value of CRP in the very early phase of stroke are ambiguous. Two prospective studies did not observe a relation between CRP levels obtained within 6 or $12 \mathrm{~h}$ after symptom onset and death or dependency at follow-up [27, 30]. Both studies
Table 3 Level-risk relationship CRP and outcome

\begin{tabular}{lll}
\hline & $\mathrm{OR}^{\mathrm{a}}(95 \% \mathrm{CI})$ & Adjusted $\mathrm{OR}^{\mathrm{a}, \mathrm{b}}(95 \% \mathrm{CI})$ \\
\hline Poor outcome (mRS > 2) & $1.6(1.2-2.2)$ & $1.3(0.9-1.9)$ \\
Death & $2.1(1.5-3.0)$ & $1.9(1.2-2.8)$ \\
\hline a ORs were expressed per 1 unit increase in logarithmically trans- \\
formed CRP levels \\
b Adjusted for age, sex, NIHSS score, cigarette smoking, diabetes \\
mellitus, hypertension, statin use, and stroke subtype
\end{tabular}

were rather small (127 and 111 patients) and may therefore have lacked the power to detect an association. In addition, one of these studies included only patients treated with rtPA [27].

In line with our results, three other studies found an association between CRP and outcome. In one of these studies, CRP was measured within $24 \mathrm{~h}$ of stroke onset, and $25 \%$ of the patients had a transient ischemic attack (TIA) instead of a stroke, which may have influenced the observed association [6]. In addition, only the relation between CRP and mortality, and not disability, was studied. Other studies included only patients aged 75 years or older [18], or patients who had a middle cerebral artery occlusion and received rt-PA [20]. In the latter, an association with mortality was found, but functional outcome was not assessed [20].

The strengths of the present study are its large sample size, robust outcome measures and early CRP measurement, which increase the relevance of our findings. Furthermore, detailed information on confounders was available.

Some methodological limitations should be discussed. First, this study was part of a larger clinical trial, and not designed to evaluate the prognostic value of CRP with regard to clinical outcome in acute ischemic stroke. As a consequence, a detailed history of inflammatory conditions was not recorded.

Levels were determined with different analyzers, which may have resulted in a systematic error. For this reason, measurements performed with analyzers with an interassay coefficient of variation $\geq 7.5 \%$ or that demonstrated bias relative to the other participating centers were excluded from further analysis. Secondly, the lowest detection limit for CRP varied from 1 to $7 \mathrm{mg} / \mathrm{L}$ among the centers. Therefore, CRP levels had to be dichotomized. This makes it more difficult to compare our results with previous studies. However, in three of the five studies that assessed the relation between CRP levels in the very early phase of acute stroke and clinical outcome, a similar cut-off point level was selected [20, 27, 30]. Furthermore, all CRP values were recoded with 7 as the lower bound, in order to study a possible level-risk relationship. 
A fourth issue might be that rather few patients with very severe stroke were included, which may affect the generalisability of the results.

In patients with ischemic stroke, increased levels of CRP may reflect a pre-existing degree of atherosclerosis or the presence of vascular risk factors. We found that patients with higher levels of CRP were more often smokers and more frequently had hypertension, diabetes mellitus, or atrial fibrillation. Furthermore, cardioembolic strokes were observed more often in patients with higher levels of CRP. Moreover, patients with $\mathrm{CRP} \geq 7 \mathrm{mg} / \mathrm{L}$ used statins less often than patients with low CRP levels, suggesting that drugs in this class reduce levels of CRP. These findings are supported by previous studies [2, 10, 17, 18, 23, 24].

Why could CRP concentration be a prognostic factor for poor outcome and death? Early after onset of ischemic stroke, increased CRP levels may reflect an accompanying inflammatory reaction. Inflammatory processes play an important role in the pathophysiology of ischemic stroke [19]. Cerebral ischemia triggers an inflammatory response characterized by activation and release of acute phase proteins such as C-reactive protein (CRP) and cytokines [4, 16, 19]. The inflammatory processes may start within $2 \mathrm{~h}$ after stroke onset and sustain for days [25], and may contribute to ischemic brain damage even in that early stage [11].

Elevated CRP levels may be a reflection of the extent of brain injury. In our study, patients with CRP levels $\geq 7 \mathrm{mg} / \mathrm{L}$ had higher NIHSS scores on admission. Previous studies have shown that patients with increased CRP levels have larger infarctions [25]. Although patients with CRP levels $\geq 7 \mathrm{mg} / \mathrm{L}$ taken as a group had worse outcomes at 3 months as assessed with the mRS, multiple logistic regression modeling indicated that the adverse outcome in this group remained even after adjustment for initial stroke severity by NIHSS score and multiple other risk factors for poor outcome. This suggests that CRP not only reflects the amount of tissue damage, but may also indicate a state of enhanced risk due to increased inflammation or cytokine excess. Interestingly, recent experimental studies have shown that CRP itself may contribute to secondary brain damage after focal cerebral ischemia, possibly via a complement-mediated exacerbation of tissue injury [13, 22]. In rats, treatment with human CRP after middle cerebral artery occlusion resulted in larger infarcts [13]. Similar results have been observed in experimental models of myocardial infarction [14].

It is therefore conceivable that increased levels of CRP following stroke are not only a consequence of brain infarction, but contribute to ischemic damage as well.

Increased CRP levels following ischemic stroke may also reflect concurrent infections. Secondary infections are common in the first week of stroke and are associated with poor outcome $[3,11,12]$, but they usually occur more than $12 \mathrm{~h}$ after stroke onset. In our study, only two clinically overt infections were reported within $24 \mathrm{~h}$ after stroke onset. In addition, we excluded patients in whom the CRP level exceeded 2 SD above the mean, who may have had an infection before stroke onset. Furthermore, exclusion of patients developing an early infection during hospitalization did not substantially affect the relation between CRP levels and poor functional outcome or death.

The use of biomarkers as predictors of stroke lesion evolution and prognosis is becoming increasingly important, as they may be valuable tools in the search for an optimal management of stroke patients. The present study confirms results from previous studies that have advocated CRP as a powerful prognostic marker in patients with ischemic stroke $[6,8,9,15,18,20,21,25,30]$. It may provide important prognostic information beyond conventional clinical parameters. Further studies are needed to assess whether CRP is also a predictor of outcome after stroke.

Moreover, the fact that animal studies have found that CRP might exacerbate brain tissue damage following ischemic stroke, might stimulate research into the underlying pathogenetic mechanisms and development of new, more targeted, medical treatments for acute ischemic stroke.

\section{Conclusion}

Elevated CRP levels in the very early phase of acute ischemic stroke are independent prognostic factors for poor outcome at 3 months.

Acknowledgments The PAIS trial was sponsored by the Netherlands Heart Foundation, grant number 2002B148. We are grateful to all patients, secretaries, and neurologists who contributed to this study. All patients participated in the PAIS trial; written informed consent was obtained from all patients or from their legal representatives for inclusion in the trial and for follow-up. The study was performed in accordance with the ethical standards laid down in the 1964 Declaration of Helsinki.

Conflict of interest statement The authors declare no conflict of interest.

Open Access This article is distributed under the terms of the Creative Commons Attribution Noncommercial License which permits any noncommercial use, distribution, and reproduction in any medium, provided the original author(s) and source are credited.

\section{Appendix: Participating centres with names of investigators}

Meander MC Amersfoort (HMA van Gemert), Erasmus MC Rotterdam (DWJ Dippel), UMC Utrecht (HB van der Worp), Sint Franciscus Gasthuis Rotterdam (FH Vermeij), Slotervaart Ziekenhuis Amsterdam (VIH Kwa), Gelre 
ziekenhuizen Apeldoorn (HP Bienfait), TweeSteden ziekenhuis Tilburg (BPW Jansen), Sint Elisabeth Ziekenhuis Tilburg (PLM de Kort), Westfriesgasthuis Hoorn (TC van der Ree), Maasstad ziekenhuis Rotterdam (R Saxena), Ziekenhuis Bethesda Hoogeveen (PG Oomes), Dirksland Ziekenhuis Dirksland (UW Huisman), Sint Lucas Andreas Ziekenhuis Amsterdam (EJ Wouda), Martini Ziekenhuis Groningen (C Bouwsma), Catharina Ziekenhuis Eindhoven (K Keizer) Albert Schweitzer ziekenhuis Dordrecht (RP Kleyweg/H Kerkhoff), Amphia Ziekenhuis Breda (HBC Verbiest/SLM Bakker), Rijnland Ziekenhuis Leiderdorp (ELLM De Schryver), Diakonessenhuis Utrecht (RCJM Donders), Slingeland Ziekenhuis Doetinchem (RA van der Kruijk), IJsselland Ziekenhuis Capelle aan den Ijssel (J Heerema), Jeroen Bosch Ziekenhuis Den Bosch (RAJAM Bernsen), Ziekenhuis Hilversum Hilversum (D Herderschêe), Diaconessenhuis Meppel (EJW Keuter), Vlietlandziekenhuis Schiedam (WC Baart), Spaarne Ziekenhuis Hoofddorp (RJ Meijer), Beatrixziekenhuis Gorinchem (RB Alting van Geusau), Streekziekenhuis Koningin Beatrix Winterswijk (JP de Ruiter), Wilhelmina Ziekenhuis Assen (JN Wessel/AE Bollen).

\section{References}

1. Adams HP, Bendixen BH, Kappelle LJ et al (1993) Classification of subtype of acute ischemic stroke. Definitions for use in a multicenter clinical trial. TOAST. Trial of Org 10172 in Acute Stroke Treatment. Stroke 24:35-41

2. Albert MA, Danielson E, Rifai N et al (2001) Effect of statin therapy on C-reactive protein levels: the pravastatin inflammation/CRP evaluation (PRINCE): a randomized trial and cohort study. JAMA 286:64-70

3. Aslanyan S, Weir CJ, Diener HC et al (2004) Pneumonia and urinary tract infection after acute ischaemic stroke: a tertiary analysis of the GAIN International trial. Eur J Neurol 11:49-53

4. Barone FC, Feuerstein GZ (1999) Inflammatory mediators and stroke: new opportunities for novel therapeutics. J Cereb Blood Flow Metab 19:819-834

5. Brott T, Adams HP, Olinger CP et al (1989) Measurements of acute cerebral infarction: a clinical examination scale. Stroke 20:864-870

6. Christensen H, Boysen G (2004) C-reactive protein and white blood cell count increases in the first $24 \mathrm{~h}$ after acute stroke. Cerebrovasc Dis 18:214-219

7. den Hertog HM, van der Worp HB, van Gemert HM et al (2008) Correction: PAIS: paracetamol (acetaminophen) in stroke; protocol for a randomized, double blind clinical trial. [ISCRTN74418480]. BMC Cardiovasc Disord 8:29

8. Di Napoli M, Papa F, Bocola V (2001) C-reactive protein in ischemic stroke: an independent prognostic factor. Stroke 32:917-924

9. Di Napoli M, Papa F, Bocola V (2001) Prognostic influence of increased C-reactive protein and fibrinogen levels in ischemic stroke. Stroke 32:133-138

10. Di Napoli M, Schwaninger M, Cappelli R et al (2005) Evaluation of C-reactive protein measurement for assessing the risk and prognosis in ischemic stroke: a statement for health care professionals from the CRP Pooling Project members. Stroke 36:1316-1329

11. Emsley HC, Hopkins SJ (2008) Acute ischemic stroke and infection: recent and emerging concepts. Lancet Neurol 7:341353

12. Emsley HC, Smith CJ, Gavin CM et al (2003) An early and sustained peripheral inflammatory response in acute ischemic stroke: relationships with infection and atherosclerosis. J Neuroimmunol 139:93-101

13. Gill R, Kemp JA, Sabin C, Pepys MB (2004) Human C-reactive protein increases cerebral infarct size after middle cerebral artery occlusion in adult rats. J Cereb Blood Flow Metab 24:1214-1218

14. Griselli M, Herbert J, Hutchinson WL et al (1999) C-reactive protein and complement are important mediators of tissue damage in acute myocardial infarction. J Exp Med 190:1733-1740

15. Kocer A, Canbulat C, Gozke E et al (2005) C-reactive protein is an indicator for fatal outcomes in first-time stroke patients. Med Sci Monit 11:CR540-CR544

16. Kushner I, Agrawal A (2007) CRP can play both pro-inflammatory and anti-inflammatory roles. Mol Immunol 44:670-671

17. Ladenvall C, Jood K, Blomstrand C et al (2006) Serum C-reactive protein concentration and genotype in relation to ischemic stroke subtype. Stroke 37:2018-2023

18. Masotti L, Ceccarelli E, Forconi S et al (2005) Prognostic role of C-reactive protein in very old patients with acute ischaemic stroke. J Intern Med 258:145-152

19. McColl BW, Allan SM, Rothwell NJ (2007) Systemic inflammation and stroke: aetiology, pathology and targets for therapy. Biochem Soc Trans 35:1163-1165

20. Montaner J, Fernandez-Cadenas I, Molina CA et al (2006) Poststroke C-reactive protein is a powerful prognostic tool among candidates for thrombolysis. Stroke 37:1205-1210

21. Muir KW, Weir CJ, Alwan W et al (1999) C-reactive protein and outcome after ischemic stroke. Stroke 30:981-985

22. Pepys MB, Hirschfield GM, Tennent GA et al (2006) Targeting C-reactive protein for the treatment of cardiovascular disease. Nature 440:1217-1221

23. Ridker PM, Danielson E, Fonseca FA et al (2008) Rosuvastatin to prevent vascular events in men and women with elevated Creactive protein. N Engl J Med 359:2195-2207

24. Ridker PM, Rifai N, Pfeffer MA et al (1999) Long-term effects of pravastatin on plasma concentration of C-reactive protein. The Cholesterol and Recurrent Events (CARE) Investigators. Circulation 100:230-235

25. Smith CJ, Emsley HC, Gavin CM et al (2004) Peak plasma interleukin- 6 and other peripheral markers of inflammation in the first week of ischaemic stroke correlate with brain infarct volume, stroke severity and long-term outcome. BMC Neurol 4:2

26. Smith CJ, Emsley HC, Vail A et al (2006) Variability of the systemic acute phase response after ischemic stroke. J Neurol Sci 251:77-81

27. Topakian R, Strasak AM, Nussbaumer K et al (2008) Prognostic value of admission C-reactive protein in stroke patients undergoing iv thrombolysis. J Neurol 255:1190-1196

28. van Breda EJ, van der Worp HB, van Gemert HM et al (2005) PAIS: paracetamol (acetaminophen) in stroke; protocol for a randomized, double blind clinical trial [ISRCTN 74418480]. BMC Cardiovasc Disord 5:24

29. van Swieten JC, Koudstaal PJ, Visser MC et al (1988) Interobserver agreement for the assessment of handicap in stroke patients. Stroke 19:604-607

30. Winbeck K, Poppert H, Etgen T et al (2002) Prognostic relevance of early serial C-reactive protein measurements after first ischemic stroke. Stroke 33:2459-2464 